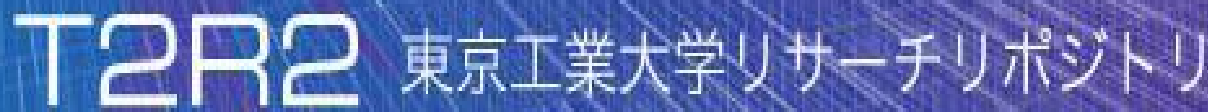

\section{Tokyo Tech Research Repository}

\section{論文 /著書情報 \\ Article /Book Information}

\begin{tabular}{|c|c|}
\hline Title & $\begin{array}{l}\text { Fabrication of Periodic Arrays of Top-Gathering Titania-O rganic Hybrid } \\
\text { Pillars Derived from Multi-Beam Laser Interference }\end{array}$ \\
\hline Authors & Hiroyo Segawa, Hiroaki Misawa, Tetsuji Yano, Shuichi Shibata \\
\hline Citation(English) & SPIE, Vol. 6106, No., pp. 61060N \\
\hline 発行日 /Pub. date & 2006, \\
\hline DOI & http://dx.doi.org $/ 10.1117 / 12.647213$ \\
\hline 権利情報 /Copyright & $\begin{array}{l}\text { 本著作物の著作権はSociety of Photo-O ptical Instrumentation } \\
\text { Engineersに帰属します。 } \\
\text { Copyright } 2006 \text { Society of Photo-O ptical Instrumentation Engineers. } \\
\text { One print or electronic copy may be made for personal use only. } \\
\text { Systematic reproduction and distribution, duplication of any material in } \\
\text { this paper for a fee or for commercial purposes, or modification of the } \\
\text { content of the paper are prohibited. }\end{array}$ \\
\hline
\end{tabular}




\title{
Fabrication of Periodic Arrays of Top-Gathering Titania-organic Hybrid Pillars Derived from Multi-beam Laser Interference
}

\author{
Hiroyo Segawa $^{a, b}$, Hiroaki Misawa $^{c}$, Tetsuji Yano ${ }^{a}$ and Shuichi Shibata ${ }^{a}$ \\ a Tokyo Institute of Technology, 2-12-1 O-okayama, Meguro-ku, Tokyo, 152-8550, Japan \\ ${ }^{b}$ Precursory Research for Embryonic Science Technology (PRESTO), Japan Science and \\ Technology Corporation (JST), Kawaguchi-shi, Saitama, Japan \\ ${ }^{c}$ CREST-JST, Research Institute for Electronic Science, Hokkaido University, N21W10, \\ Kita-ku, Sapporo, 001-0021, Japan
}

\begin{abstract}
Multi-beam laser interference (MLI) lithography is known to be one of the fabrication techniques of photonic crystals. In MLI lithography, laser beams are interfered on a scale of the wavelength of light and are irradiated to photosensitive films. We have paid attention to photosensitive $\mathrm{TiO}_{2}$-organic hybrid film, which has high refractive index. $\mathrm{TiO}_{2}$-organic hybrid periodic pillar patterns were fabricated by MLI lithography. The $\mathrm{TiO}_{2}$ hybrid film, which was prepared from Ti-alkoxide and $\beta$-diketone by the sol-gel method, was exposed to the interference pattern of femtosecond pulses at $800 \mathrm{~nm}$ wavelength. After laser irradiation, the unirradated portion was removed by the development and rinse. Two-dimensional periodic standing alone pillars and $2 \times 2$ and $3 \times 3$ top-gathering pillars, which were gathered at the top by means of self-organization were formed by changing conditions such as laser irradiation time and film thickness. The pillar patterns depended upon the rinse liquid, the diameter, and the height of pillars. The top-gathering pillars are applicable for diffractive optics.
\end{abstract}

Keywords: self-organization, top-gathering, capillary force and multi-beam laser interference lithography

\section{INTRODUCTION}

Two-dimensional (2D) periodic arrays on the scale of the wavelength of light have been applied to various devices such as diffraction gratings and photonic crystals (PCs). ${ }^{1-3}$ Many techniques have been used to fabricate periodic arrays for PCs. Multi-beam laser interference (MLI) lithography is one of the useful techniques of fabrication of PCs. ${ }^{4-7}$ In MLI lithography, photosensitive materials are exposed to the light interference pattern, are developed and rinsed in an appropriate liquid, resulting in periodic arrays. Generally, in conventional lithography, patterns of the photosensitive material receive strong mechanical force during drying of rinse liquid, then the patterns become unstable, and finally collapse or are distorted as the aspect ratio of pillar height to pitch increases. ${ }^{8-10}$ The capillary force due to the surface tension of the rinse solvent has potential to make new patterns of photosensitive materials.

Recently, 2D patterns of polyimide pillars with submicrometer repetitions have been fabricated by electronbeam lithography, and bunching structures of such pillars could be produced when the diameter of the pillars is very small. ${ }^{11}$ In the bunching structures, several pillars are gathered at the top by means of self-organization. We also reported "top-gathering" pillar patterns of an organic-inorganic hybrid material fabricated by UV light lithography. ${ }^{12}$ When the capillary force was controlled by changing the distance of the neighboring pillars, four pillars were gathered at the top, and their top-gathering pillars were arranged periodically. The top-gathering pillar patterns are attractive to use as templates for fabricating new structures such as pyramidal structures for luminescence components or photonic devices such as tunable photonic crystals.

In our previous work, organic-inorganic hybrid materials with photosensitive organic molecules such as unsaturated hydrocarbon were used to fabricate 2D periodic pillar patterns with submicrometer diameter using

Further author information: (Send correspondence to Hiroyo Segawa)

Hiroyo Segawa: E-mail: hsegawa@ceram.titech.ac.jp, Telephone: +81 (0)3 5734 S2523

Photon Processing in Microelectronics and Photonics V, edited by Tatsuo Okada, Craig B. Arnold

Michel Meunier, Andrew S. Holmes, David B. Geohegan, Frank Träger, Jan J. Dubowski

Proc. of SPIE Vol. 6106, 61060N, (2006) · 0277-786X/06/\$15 · doi: 10.1117/12.647213

Proc. of SPIE Vol. 6106 61060N-1 
MLI lithography by femtosecond (fs) laser. ${ }^{7,13}$ The photosensitive hybrid patterns can be changed to inorganic patterns after the calcination; removal of organic components from the initial patterns of hybrid materials. ${ }^{14,15}$ The top-gathering pillar patterns of organic-inorganic hybrid materials are useful in the fabrication of complex inorganic patterns, which cannot be obtained by conventional lithography.

Especially, $\mathrm{TiO}_{2}$-organic hybrid materials are advantageous, because new periodic patterns of $\mathrm{TiO}_{2}$ that has high refractive index are applicable for photonic devices. We have reported fabrications of photosensitive $\mathrm{TiO}_{2}{ }^{-}$ organic hybrid films, which were prepared from a Ti alkoxide modified with a $\beta$-diketone and an unsaturated hydrocarbon, by the sol-gel method. ${ }^{13,16}$ In the $\mathrm{TiO}_{2}$-organic hybrid film, $\beta$-diketonate chelate between $\mathrm{Ti}$ alkoxide and $\beta$-diketone was decomposed by multi-photon absorption (MPA) of fs laser. The solubility in an appropriate liquid of the exposed parts decreased by the decomposition of the $\beta$-diketonate chelate. After the development using the appropriate liquid, $\mathrm{TiO}_{2}$-organic hybrid periodic pillars could be fabricated. The topgathering pillar patterns of the $\mathrm{TiO}_{2}$-organic hybrid material has not been reported and conditions to form the top-gathering pillars have not been clarified yet.

In this paper, we report formation conditions of standing alone pillars and top-gathering pillars, which are composed of a certain number of pillars gathered at the top, of $\mathrm{TiO}_{2}$-organic hybrid materials by MLI lithography using fs laser. One of optical properties, diffraction images of a few kinds of fabricated periodic pillars such as standing alone pillars and top-gathering pillars are observed.

\section{EXPERIMENTAL}

$\mathrm{TiO}_{2}$-organic hybrid gel films were prepared by the sol-gel method. Titanium tetra- $n$-butoxide $\left(\mathrm{Ti}(\mathrm{O}-n \mathrm{Bu})_{4}\right.$, Soekawa Chemical Co. Ltd.) was reacted with 2-(methacryloyloxy) ethyl acetoacetate (MEAcAc, Acros Organics), which was a $\beta$-diketone. The molar ratio of $\mathrm{Ti}(\mathrm{O}-n \mathrm{Bu})_{4}$ and MEAcAc was 1:1. After stirring the solution for $15 \mathrm{~min}$ at room temperature, $\mathrm{H}_{2} \mathrm{O}$ was added dropwise to the sol. The molar ratio of $\mathrm{H}_{2} \mathrm{O}$ to $\mathrm{Ti}(\mathrm{O}-n \mathrm{Bu})_{4}$ was 2:1. The sol was stirred for $3 \mathrm{~h}$ at room temperature. The sol was then spin-coated for 20 sec on glass substrates. The spinning speed was controlled as to form films of 1.4 to $4.3 \mu \mathrm{m}$ in thickness. The hybrid films were baked at $80{ }^{\circ} \mathrm{C}$ for $10 \mathrm{~min}$.

The film was then exposed to the interfering pattern of fs laser pulses, which were obtained from Ti:sapphire regenerative amplifier (wavelength of $800 \mathrm{~nm}$, pulse duration of $150 \mathrm{fs}$, and repetition rate of $1 \mathrm{kHz}$ ). The optical setup has been previously reported. ${ }^{6}$ Briefly, a diffractive beam splitter (G1023A MEMS Optical Inc.) divides the input laser pulses, and the four diagonal beams were focused on the film by a two-lens system. The interference light set at a $1.0 \mu \mathrm{m}$ pitch by the interference angle (the angle between the main optical axis and the other beam in air). The single-pulse energy (sum of all beams) was 20-45 $\mu \mathrm{J}$. After laser irradiation for 1-15 min, the films were developed in 2-ethoxyethanol for $1 \mathrm{~min}$ to remove unirradiated portion. After that, the remaining patterns were rinsed by water or 2-ethoxyethanol and dried. The remaining patterns on the substrate were observed by a scanning electron microscope (SEM; JSM-5310,JSM-6700FT; JEOL).

Diffraction images from the fabricated periodic pillar patterns were observed by an optical setup ${ }^{17}$ as shown in Fig. 1. A real image of the periodic pillar patterns on the glass substrate was magnified by an objective lens

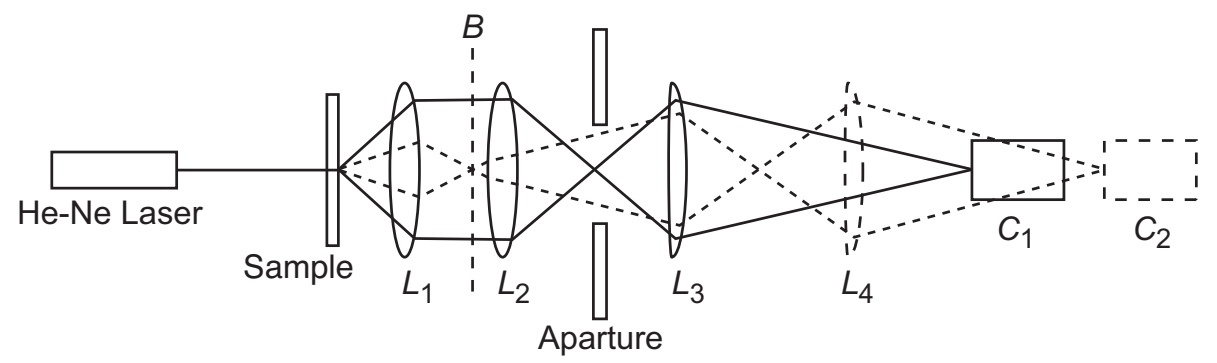

Figure 1. Optical setup for measuring diffraction images. $L_{1}$, objective lens $(\mathrm{NA}=0.90) ; L_{2}$, imaging lens; $L_{3}$, lens $(f=70 \mathrm{~mm}) ; L_{4}$, lens $(f=50 \mathrm{~mm}) ; C_{1}$ and $C_{2}$, CCD camera; $B$, back-focal plane of $L_{1}$. 
$L_{1}$ with a numerical aperture (NA) of 0.90 and imaging lens $L_{2}$. Optical path was illustrated by a solid line in the figure. The real image was focused on an aperture and observation area of the periodic pillar patterns was selected by the aperture $(\phi=1 \mathrm{~mm})$. The selected real image was magnified by a lens $L_{3}$ and observed by a charge-coupled-device (CCD) camera $C_{1}$. A diffraction image of the selected pillars was observed through optical path illustrated by a dashed line. The periodic pillar patterns were illuminated with a beam of He-Ne laser (wavelength of $633 \mathrm{~nm}$ ). The scattered light from the periodic patterns was collected with the lens $L_{1}$. At the back focal point $B$ of $L_{1}$, the Fourier pattern of the real image was formed. The image corresponded to a diffraction image. The diffraction image was magnified with lenses $L_{2}, L_{3}$ and $L_{4}$, and then projected onto a CCD camera $C_{2}$.

\section{RESULTS}

Top view SEM images of $\mathrm{TiO}_{2}$-organic hybrid pillars are shown in Fig. 2. They were produced by an irradiation of $40 \mu \mathrm{J}$ single-pulse energy on the film of $1.4 \mu \mathrm{m}$ in thickness and a rinse by water. In Fig. 2(a) and (b), the pillars fabricated by irradiations for (a) $1 \mathrm{~min}$ and (b) 5 min. In Fig. 2(a), most of pillars stood vertically, but several pillars fell down and gathered irregularly at the top. In Fig. 2(b), all pillars were standing perpendicular to the substrate, and they were arranged with a tetragonal lattice. From a comparison of Fig. 2 (a) and (b), the diameter of the pillars increased with increasing the irradiation time. This means that the photoreaction proceeded during the laser irradiation and the photopolymerized area expanded.

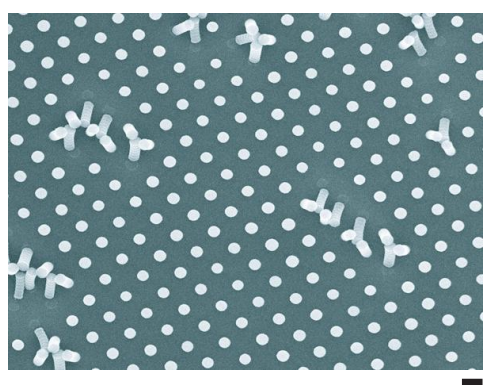

(a)

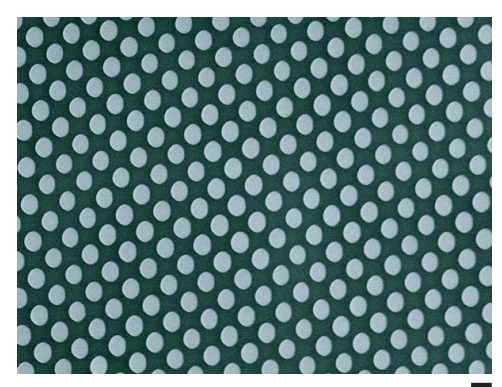

(b)

Figure 2. SEM images of $\mathrm{TiO}_{2}$-organic hybrid pillars fabricated by different irradiation conditions and rinsed by water. Irradiations are $45 \mu \mathrm{J}$, (a) for $1 \mathrm{~min}$ and (b) $5 \mathrm{~min}$. The bar is $1 \mu \mathrm{m}$.

The percentage of the standing pillars in an array is plotted against the diameter $D$ of the pillars in Fig. 3 . It was difficult for pillars to keep standing vertically as their diameters decreased. Some of the pillars fell down and were gathered at the top when the pillar diameter was smaller than $0.7 \mu \mathrm{m}(D<0.7 \mu \mathrm{m})$.

SEM images of $\mathrm{TiO}_{2}$-organic hybrid pillars fabricated by the rinse by 2-ethoxyethanol, are shown in Fig. 4. They were produced by irradiations of $30 \mu \mathrm{J}$ single-pulse energy on the film of $1.4 \mu \mathrm{m}$ in thickness. Figs. 4(a), (b) and (c) show the pillars fabricated by the irradiations for (a) $140 \mathrm{sec}$, (b) $100 \mathrm{sec}$, and (c) $60 \mathrm{sec}$. The diameter of the pillars decreased with decreasing the irradiation time. Figs. 4(a-1) and (b-1) are top views and Figs. 4(a-2) and (b-2) are their corresponding views from an angle of $20^{\circ}$ with respect to the substrate. In Fig. $4(\mathrm{a})$, all pillars were standing perpendicular to the substrate, and they formed a $2 \mathrm{D}$ periodic pattern with a tetragonal lattice. In Fig. 4(b), the pillars were gathered at the top by means of self-organization, and $2 \times 2$ "top-gathering" units were formed. The top-gathering units were arranged periodically. In Fig. 4(c), the many pillars were gathered at the top, but the top-gathering units of dozens of pillars did not arrange periodically.

Percentage of standing alone pillars, $2 \times 2$ top-gathering pillars and $3 \times 3$ top-gathering pillars in an array was plotted against the diameter of the pillar $D$ in Fig. 5. The height of the pillars are (a) $1.4 \mu \mathrm{m}$, (b) $2.1 \mu \mathrm{m}$, and (c) $3.0 \mu \mathrm{m}$. In Fig. 5(a) $(h=1.4 \mu \mathrm{m})$, the pillars stood vertically to the substrate when the diameter was over $0.8 \mu \mathrm{m}(D \geq 0.8 \mu \mathrm{m})$, and the $2 \times 2$ and the $3 \times 3$ top-gathering pillars were formed when the diameter was between 0.5 and $0.8 \mu \mathrm{m}(0.5<D \leq 0.8 \mu \mathrm{m})$. The percentage of the $2 \times 2$ top-gathering pillars peaked near about $0.60 \mu \mathrm{m}$ in the diameter $(D=0.60 \mu \mathrm{m})$, whose diameter was called $D_{\max }$ in the following. $D_{\max }$ represented 


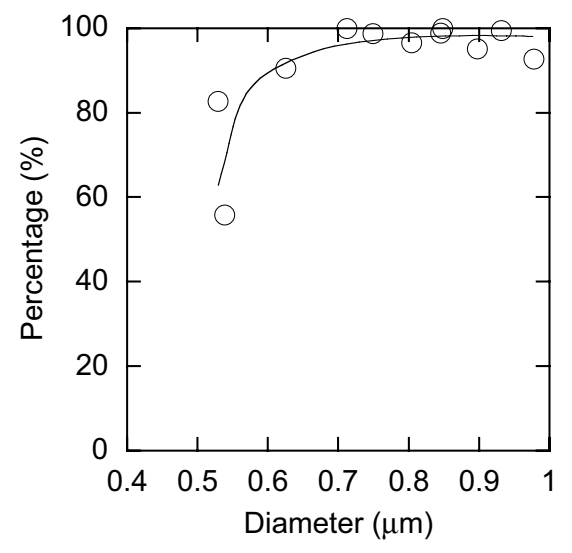

Figure 3. Percentage of the standing alone pillars of $1.4 \mu \mathrm{m}$ in height as a functional of the pillar diameter. Water was used for the rinse liquid.

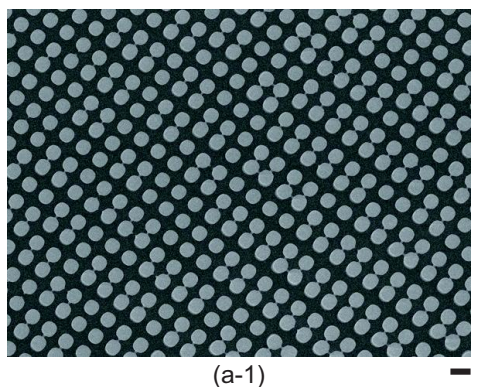

$(\mathrm{a}-1)$

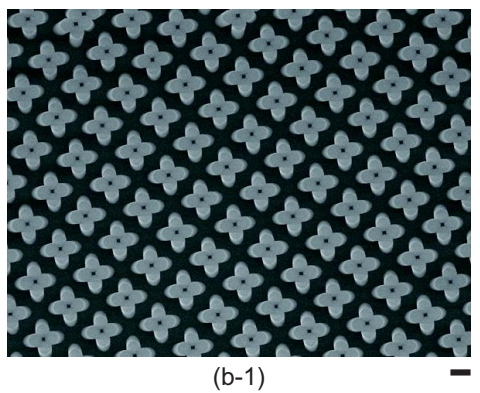

(b-1)

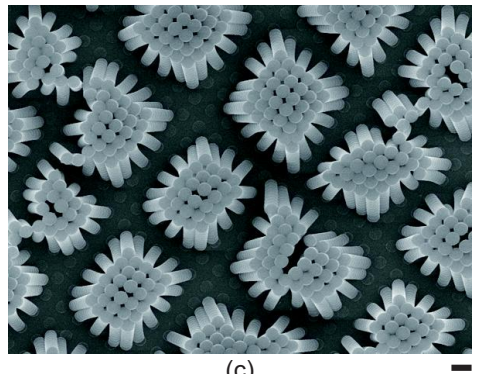

(c)

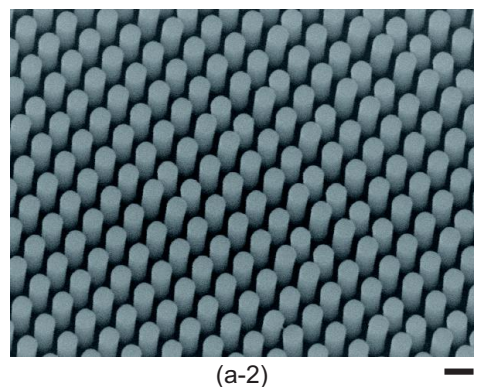

$(\mathrm{a}-2)$

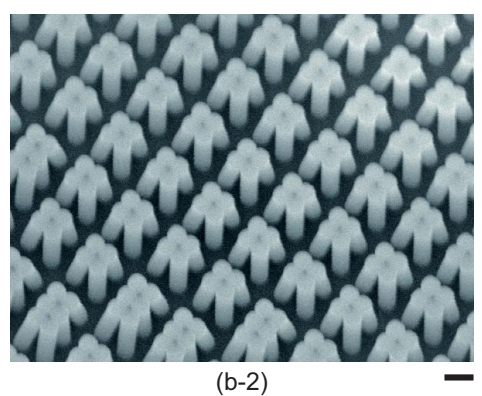

Figure 4. SEM images of $\mathrm{TiO}_{2}$-organic hybrid pillars fabricated by different irradiation conditions and rinsed by 2ethoxyethanol. Irradiations are $30 \mu \mathrm{J}$ : (a) $140 \mathrm{sec}$, (b) $100 \mathrm{sec}$, and (c) $60 \mathrm{sec}$. The bar is $1 \mu \mathrm{m}$. 


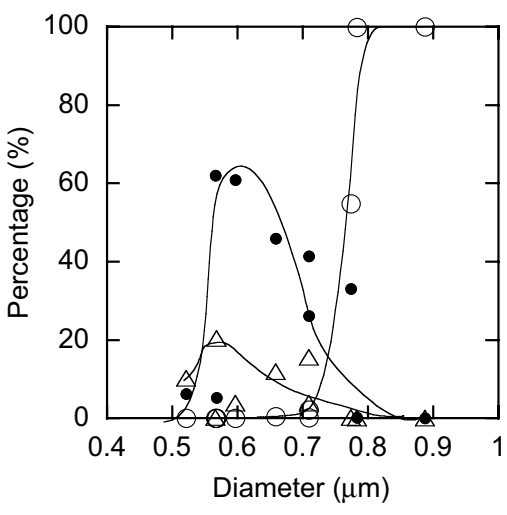

(a)

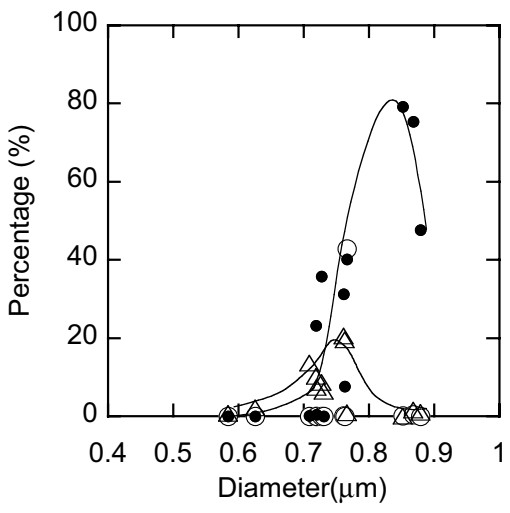

(c)

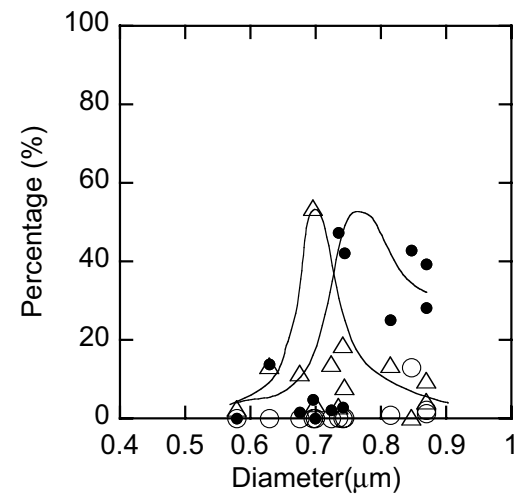

(b)

Figure 5. Percentage of the standing alone pillars (o), $2 \times 2$ top-gathering pillars $(\bullet)$ and $3 \times 3$ top-gathering pillars $(\triangle)$ in an array as a functional of the pillar diameter. The pillar height are (a) $1.4 \mu \mathrm{m}$, (b) $2.1 \mu \mathrm{m}$, and (c) $3.0 \mu \mathrm{m}$. 2-ethoxyethanol was used for the rinse liquid.

that pillars formed easily a certain top-gathering pillars such as $2 \times 2$. The percentage of the $3 \times 3$ top-gathering pillars had a peak at $0.55 \mu \mathrm{m}$ in diameter (i.e., $D_{\max }=0.55 \mu \mathrm{m}$ ). $D_{\max }$ of the $2 \times 2$ top-gathering pillars was larger than that of the $3 \times 3$. In Fig. $5(\mathrm{~b})(h=2.1 \mu \mathrm{m})$, it was very difficult to form the standing alone pillars, and the $2 \times 2$ and $3 \times 3$ top-gathering pillars were formed when the diameter of the pillar was between 0.6 and $0.9 \mu \mathrm{m}$. The percentage of the $2 \times 2$ top-gathering pillars reached to maximum when the pillar diameter was $0.80 \mu \mathrm{m}\left(D_{\max }=0.80 \mu \mathrm{m}\right)$ and that of the $3 \times 3$ had a peak at $D_{\max }=0.70 \mu \mathrm{m}$. In Fig. $5(\mathrm{c})(h=3.0 \mu \mathrm{m})$, it was also difficult to form the standing alone pillars, and the $2 \times 2$ and the $3 \times 3$ top-gathering pillars were formed when the diameter of the pillar was between 0.6 and $0.9 \mu \mathrm{m}$. The percentage of the $2 \times 2$ top-gathering patterns had a peak when the diameter was about $0.85 \mu \mathrm{m}\left(D_{\max }=0.85 \mu \mathrm{m}\right)$, and that of the $3 \times 3 \mathrm{reached}$ to maximum when the diameter was about $D=0.75 \mu \mathrm{m}\left(D_{\max }=0.75 \mu \mathrm{m}\right)$. Accordingly, $D_{\max }$ of the $2 \times 2$ top-gathering pillars was larger than that of the $3 \times 3$ pillars when the pillar height was constant, and each $D_{\max }$ of the $2 \times 2$ and the $3 \times 3$ top-gathering pillars increased with increasing the height of the pillars.

One of the optical properties, diffraction images of periodic pillars were observed using the optical setup as shown in Fig. 1. SEM images of (a) standing alone pillars, (b) $2 \times 2$ top-gathering pillars and (c) $3 \times 3$ top-gathering pillars, which were observed the diffraction images, are shown in Figs. 6(a-1), (b-1) and (c-1). The diffraction images observed by CCD camera $C_{2}$ (see in Fig. 1) are shown in Figs. 6(a-2), (b-2) and (c-2). The real images measured by $C_{1}$, which corresponded to the SEM images of Figs. 6(a-1), (b-1) and (c-1), respectively, are inserted small in the diffraction images. In Fig. 6(a-2), a central spot corresponded to the diffraction light of the zero order, and four diagonal spots corresponded to the diffraction of the first order. From Fig. 6(a-2), 


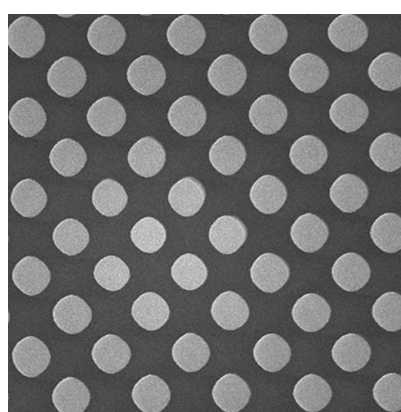

$(\mathrm{a}-1)$

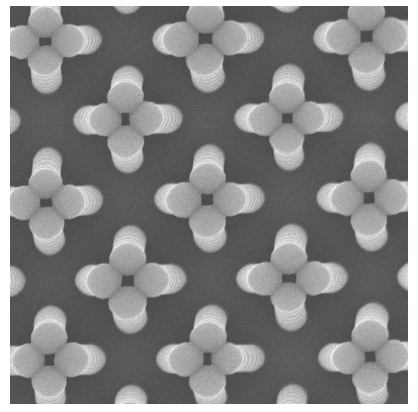

$(b-1)$

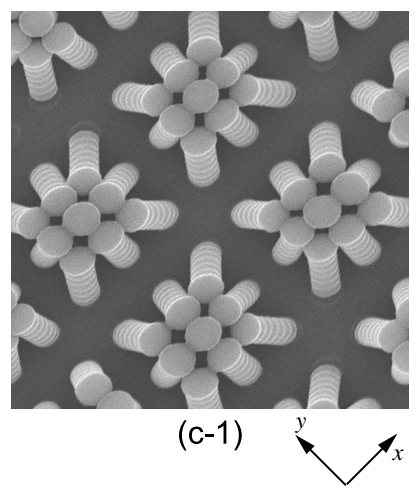

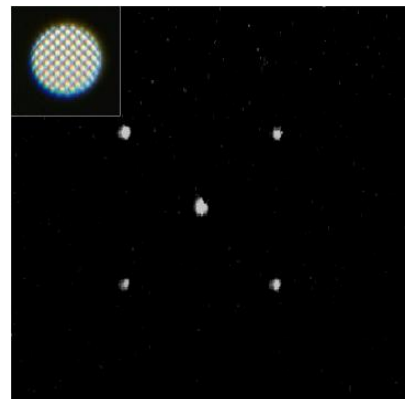

$(\mathrm{a}-2)$

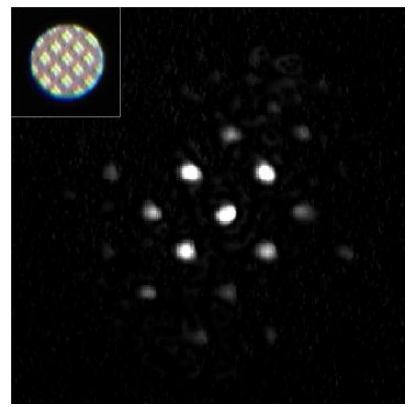

$(\mathrm{b}-2)$

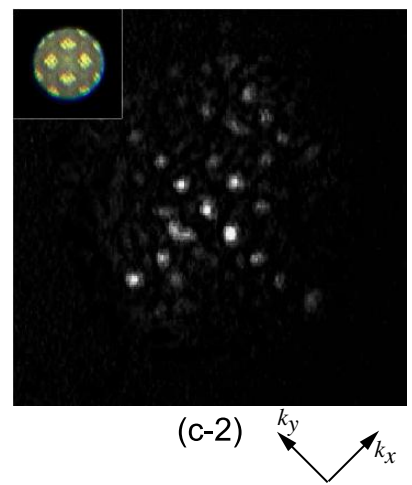

Figure 6. SEM images and diffraction images of (a) standing alone pillars, (b) $2 \times 2$ top-gathering pillars and (c) $3 \times 3$ top-gathering pillars. (a-1), (b-1) and (c-1) are SEM images of the selected pillar patterns. (a-2), (b-2) and (c-2) are diffraction images and real images inserted figures at upper left of the pillars corresponded to (a-1), (b-1) and (c-1).

(b-2) and (c-2), the diffraction spots increased and became complex with increasing number of the top-gathering pillars in a unit.

Intensity of the diffraction patterns, which was normalized by a peak intensity of the zero diffraction order, is shown in Fig. 7. The intensity of the diffraction images is shown as a function of the position along the spatial frequency, $k_{x}$ axis (see inset in Fig. 6). In Fig. 7, the zero pixel in an $x$-axis corresponded to the center spot of the diffraction image as shown in Fig. 6 . Then, the $x$-axis was proportional to the $k_{x}$. The peaks corresponded to the diffraction spots. In the case of the standing alone pillars (Fig. $7(\mathrm{a})$ ), the peaks at \pm 80 pixel were assigned to the first diffraction order. The peaks at \pm 40 pixel of the $2 \times 2$ top-gathering pillars (Fig. $7(\mathrm{~b}))$ and those at \pm 27 pixel of the $3 \times 3$ top-gathering pillars (Fig. $7(\mathrm{c})$ ) were also assigned to the first diffraction order. The first diffraction of the $2 \times 2$ top-gathering pillars appeared at the one-second of that of the standing alone pillars, and that of the $3 \times 3$ pillars appeared at the one-third. In briefly, the peak assigned to the first diffraction order 
shifted to small spatial frequency. By considering the fact that the repetition period of the $2 \times 2$ top-gathering pillars is larger than twice as that of the standing alone pillars and that of the $3 \times 3$ pillars is larger than three times (see Fig.6), it was found the diffraction images reflected the periods of the pillar arrays. The results suggest that the top-gathering arrays are useful for diffraction devices.

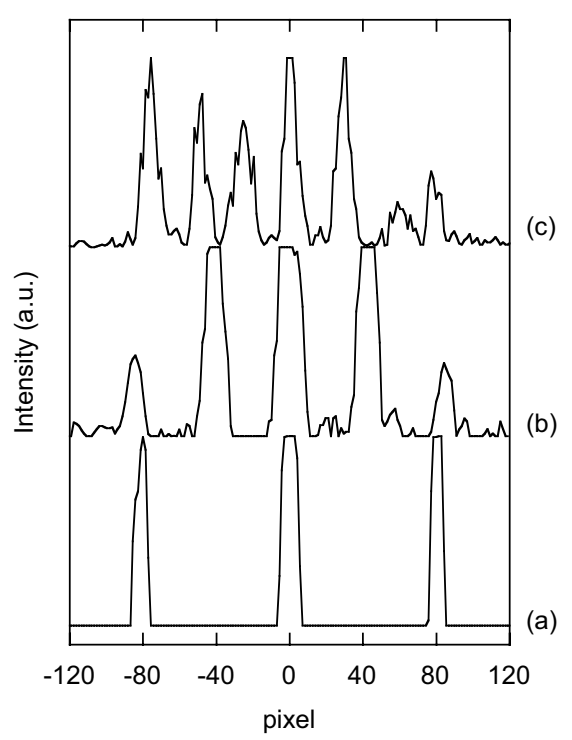

Figure 7. Normalized intensity of the diffraction images as a function of the spatial frequency, (a) standing alone pillars, (b) $2 \times 2$ top-gathering pillars and (c) $3 \times 3$ top-gathering pillars.

\section{DISCUSSION}

We could fabricate three kinds of pillar patterns: the standing alone pillars, the $2 \times 2$ top-gathering pillars and the $3 \times 3$ top-gathering pillars. The standing alone pillars could be obtained easier when the pillars were rinsed by water than that by 2-ethoxyethanol. The units of gathering pillars enlarged as the pillar height increased and the pillar diameter decreased. From these results, it was found that the pillar patterns depended on three factors: the kinds of the rinse liquid, the height and the diameter of the pillars. The three factors influenced the capillary force during drying of the rinse liquid.

When a pair of two square pillars of side length $D$ are immersed in liquid, the capillary force $P$ are expressed as, ${ }^{18}$

$$
P=\frac{2 \pi D h \sigma \cos \theta}{l_{x}}
$$

where $\sigma$ is the surface tension, $\theta$ is the contact angle of the rinse liquid, and $l_{x}$ is separated distance between neighboring pillars.

When water was used as a rinse liquid (Fig. 3), the standing alone pillars were obtained more easily than that of 2-ethoxyethanol (Fig. 5(a)). The surface tension of water is $\sigma=71.99 \mathrm{~mJ} / \mathrm{cm}^{2}$, and it is larger than that of 2-ethoxyethanol $\left(\sigma=28.35 \mathrm{~mJ} / \mathrm{cm}^{2}\right) .{ }^{19} \quad$ It was expected from eq. (1) that the pillars rinsed by water fall more easily than those by 2-ethoxyethanol, which differs from the results. The difference of pillar patterns rinsed by water and 2-ethoxyethanol could not be explained by only the surface tension. The contact angle of the rinse liquid should be considered. ${ }^{20}$ The measured contact angle $\theta$ of water for the hybrid film was about 
$67^{\circ}$ and it was smaller than that of 2-ethoxyethanol that was under $5^{\circ}$. The capillary force of 2-ethoxyethanol calculated from eq. (1) was a little larger than that of water when the other parameters $\left(h, D\right.$, and $\left.l_{x}\right)$ were constant. By the consideration of not only the surface tension but also the contact angle, it can explain that the pillars rinsed by 2-ethoxyethanol fall more easily than those by water.

The units of the top-gathering pillars enlarged, i.e., the numbers of the top-gathering pillars increased from $2 \times 2$ to $3 \times 3$ with increasing the height of the pillar $h$ (Fig. 5). From eq. (1), the capillary force increases with increasing $h$. By the increase of the capillary force, the pillars fell easily down and the units of the top-gathering pillars enlarged.

On the other hand, the number of pillars in a top-gathering unit decreased with increasing of the pillar diameter $D$. This means that it is difficult for the pillars to fall down when the diameter $D$ increases. When the pillar diameter is large, the capillary force increases based on eq. (1). In this case, the distance between the center of neighboring pillars was constant independently of the pillar patterns, so the separated distance between neighboring pillars $l_{x}$ decreased with increasing the diameter of pillars $D$. The decrease of $l_{x}$ influenced more strongly the capillary force than the increase of $D$, resulting in the increase of the capillary force. Thus, top-gathering pillars were formed easily with decreasing the diameter of pillars.

From the several conditions to fabricate the different pillar patterns, we clarify following factors to control the top-gathering: (1) the surface tension and the contact angle of the rinse liquid, (2) the height of the pillars and (3) the diameter.

\section{CONCLUSIONS}

In summary, we produced hybrid $\mathrm{TiO}_{2}$-organic pillar patterns by the multi-beam laser interference lithography. The standing alone pillars, the $2 \times 2$ top-gathering pillars and the $3 \times 3$ top-gathering pillars could be obtained depending on the kinds of rinse liquid, the height and the diameter of the pillars, which influenced the capillary force during drying the rinse liquid. The top-gathering pillars will be applicable for new tunable diffractive optics.

\section{REFERENCES}

1. H. P. Herzig ed., Micro-optics, Taylor \& Francis, Ltd., London, UK (1997).

2. J. D. Joannapoulos, P. R. Villeneuve and S. Fan, "Photonic crystals: putting a new twist on light", Nature, 386, 143-149, (1997).

3. E. Yablonovitch,"Photonic band-gap structures", J. Opt. Soc. Am. B, 10, 283-295, (1993).

4. S. Shoji, S. Kawata, "Photofabrication of three-dimensional photonic crystals by multibeam laser interference into a photopolymerizable resin", Appl. Phys. Lett., 76, 2668-2670, (2000).

5. M. Campbell, D.N. Sharp, M.T. Harrison, R.G. Denning, A.J. Turberfield, "Fabrication of photonic crystals for the visible spectrum by holographic lithography", Nature, 404, 53-55, (2000) .

6. T. Kondo, S. Matsuo, S. Juodkazis, H. Misawa, "Femtosecond laser interference technique with diffractive beam splitter for fabrication of three-dimensional photonic crystals", Appl. Phys. Lett., 79, 725-727, (2001).

7. H. Segawa, K. Yoshida, T. Kondo, S. Matsuo, H. Misawa, "Fabrication of Photonic Crystal Structures by Femtosecond Laser-Induced Photopolymerization of Organic-Inorganic Film", J. Sol-Gel Sci. Tech., 26, 10231027, (2003).

8. T. Tanaka, M. Norigami, N. Atoda, "Mechanism of Resist Pattern Collapse during Development Process", Jpn. J. Appl. Phys., 32, 6059-6064, (1993).

9. K. Deguchi, K. Miyoshi, T. Ishi, T. Matsuda, "Patterning Characteristics of a Chemically-Amplified Negative Resist in Synchrotron Radiation Lithography", Jpn. J. Appl. Phys., 31, 2954-2958, (1992).

10. M. Yamabe, "Status and issues of electron projection lithography", J. Microlitho., Microfab., Microsyst., 4, 011005, (2005).

11. A. K. Geim, S. V. Dubonos, I.V. Grigorieva, K.S. Novoselov, A. A. Zhukov, and S. Yu. Sapoval, hMicrofabricated Adhesive Mimicking Gecko Foot-Hair", Nature Mater., 2, 461-463, (2003).

12. H. Segawa, Y. Yamazaki, T. Yano, S. Shibata, "Top-Gathering Periodic Array Derived from Self-Organization of Hybrid Organic-Inorganic Pillars", Jpn. J. Ceram. Soc., 114, 120-124, (2006). 
13. H. Segawa, S. Matsuo, H. Misawa, "Fabrication of Fine-Pitch $\mathrm{TiO}_{2}$-organic Hybrid Dot Arrays Using MultiPhoton Absorption of Femtosecond Pulses", Appl. Phys. A, 79, 407-409, (2004).

14. N. Tohge, G. Zhao and F. Chiba, "Photosensitive gel films prepared by the chemical modification and their application to surface-relief gratings", Thin Solid Films, 351, 85-90, (1999).

15. M. S. M. Saifullah, H. Namatsu, T. Yamaguchi, K. Yamazaki, K. Kurihara, "Effect of Chelating Agents on High Resolution Electron Beam Nanolithography of Spin-Coatable $\mathrm{Al}_{2} \mathrm{O}_{3}$ Gel Films", Jpn. J. Appl. Phys., 38, 7052-7058, (1999).

16. H. Segawa, S. Matsuo and H. Misawa, "Laser Fabrication of Two-Dimensional Periodic Arrays of a $\mathrm{TiO}_{2}-$ Organic Hybrid Material", Proceedings of the XX ICG, O-11-030, (2004).

17. H.T. Miyazaki, H. Miyazaki, Y. Jimba, Y. Kurokawa, N. Shinya, K. Miyano, "Light diffraction from a bilayer lattice of micrspheres enhanced by specular resonance", J. Appl. Phys., 95, 793-805, (2004).

18. J. N. Israelachvili, Intermolecular and Surface Forces, Academic Press Ltd., London, 2nd ed., (1992).

19. D. R. Lide (Ed.): CRC Handbook of Chemistry and Physics, 82nd ed., p. 6-147, CRC Press Inc., Boca Raton, Florida, (1998).

20. T. Kondo, S. Juodkazis, H. Misawa, "Reduction of capillary force for high-aspect ratio nanofabrication", Appl. Phys. A, 81, 1583-1586, (2005). 